DOI 10. 18307/2016. 0613

(c) 2016 by Journal of Lake Sciences

\title{
沉水植物水槽对农村水体净化效果与机制的模拟”
}

\author{
赵建成 ${ }^{1,2}$, 杨 扬 ${ }^{1 * *}$, 钟胜强 ${ }^{1}$, 李 锟 $^{2}$, 陈小刚 ${ }^{2}$ \\ ( 1 : 暨南大学水生生物研究所,广州 510632) \\ ( 2 : 深圳市深港产学研环保工程技术股份有限公司, 深圳 518055$)$
}

\begin{abstract}
摘 要: 实验设计中试水槽装置, 模拟研究 2 种沉水植物轮叶黑藻 (Hydrilla nerticillata) 和苦草 (Vallisneria natans) 对农村 水体的净化效果, 并探讨沉水植物在水体氮、磷去除中的作用. 结果显示, 沉水植物系统均能显著降低水体中总氮、铵态 氮、硝态氮和磷酸盐浓度, 去除率分别达到 50.5\%、84.4\%、41.9\%和 $64.6 \%$, 且轮叶黑藻组选择 $20 \mathrm{~g} / \mathrm{m}^{2}$, 苦草组选择 $40 \mathrm{~g} / \mathrm{m}^{2}$ 为适种密度. 水体流经各串联单元时氮、磷去除负荷存在显著差异, 其中总氮、硝态氮、磷酸盐浓度在有植物单元高于无 植物单元, 铵态氮浓度相反, 结合单元内溶解氧浓度、硝化与反硝化细菌总数表明, 有植物单元可显著发生反硝化作用, 无植物单元可显著发生硝化作用, 有无植物串联单元更有利于氮的去除.
\end{abstract}

关键词: 沉水植物水槽; 有植物区;无植物区; 氮; 磷;农村水体; 轮叶黑藻; 苦草

\section{Simulation on rural water purification effect and mechanism with submerged macrophytes' sink}

ZHAO Jiancheng ${ }^{1,2}$, YANG Yang ${ }^{1 * *}$, ZHONG Shengqiang $^{1}$, LI Kun ${ }^{2} \&$ CHEN Xiaogang ${ }^{2}$

(1: Research Center of Hydrobiology, Jinan University, Guangzhou 510632, P.R.China)

(2: Engineering Research Center of the Ministry of Education for Tropical and Subtropical Aquatic Ecological Engineering, Shenzhen 518055, P.R.China)

Abstract: This experiment examined the purification effect of two submerged plants (Hydrilla verticillata and Vallisneria natans) on rural pond, and the nitrogen and phosphorus removal function of the plants in water, which was experimentized in pilot sink. The results showed that the plants can significantly decrease the concentration of total nitrogen, ammonium nitrogen, nitrate nitrogen, phosphate with a removing rates reached $50.5 \%, 84.4 \%, 41.9 \%, 64.6 \%$, respectively. The density of $H$. verticillata and $V$. natans setting to be $20 \mathrm{~g} / \mathrm{m}^{2}$, and $40 \mathrm{~g} / \mathrm{m}^{2}$ would be the best options. As water flew through the series unit, there was obviously difference in nitrogen and phosphorus removal efficiency. The removal rates on total nitrogen, nitrate nitrogen, phosphate in planting area were higher than the ones in open area, while to the removal rate on ammonium nitrogen, is higher in open area. Combining dissolved oxygen of the units and the total number of nitrification and denitrification bacteria, it showed that plant units may have significant denitrification, while open units have significant nitrification. Tandeming the open unit and planting unit together could have a better total nitrogen removal effect.

Keywords: Submerged macrophyte sink; planting area; open area; nitrogen; phosphorus; rural water; Hydrilla verticillata; Vallisneria natans

近年来, 随着人们对农村水体污染危害认识的逐渐提高,农村诸多源头控制及过程排水的处理技术 ${ }^{[1]}$ 等逐渐开展起来, 并收到一定的治理效果. 目前, 农村污水处理设施普遍排放标准不高, 水体中仍含有较高 的氮、磷等营养盐物质, 导致地表水体的富营养化. 因此, 需要一种近自然的深度处理技术, 以进一步降低尾 水营养物质,达到改善水体的要求.

* 国家“十二五”科技支撑计划项目 (2012BAJ21B07) 资助. 2015-09-01 收稿; 2015-12-02 收修改稿. 赵建成 (1988 ), 男, 硕士研究生; E-mail:476675687@ qq.com.

** 通信作者;E-mail: yangyang@ scies.org. 
沉水植物是一种根、茎、叶全部位于水层下面营固着生活的大型水生植物, 是水生生态系统重要组成部 分, 作为水生生态系统的生产者, 在生长过程中可通过直接吸收或间接作用显著降低水体中的氮、磷营养盐 浓度, 并释放出氧气, 同时分泌化感物质抑制藻类的生长, 对水体环境起到净化作用 ${ }^{[2-3]}$. 目前, 利用沉水植 物净化水体氮、磷具有高效、低消耗且环境安全等优点, 越来越受到该领域的广泛重视和研究 ${ }^{[4-5]}$. 雷泽湘 等 ${ }^{[6]}$ 运用苦草等大型沉水植物围隔实验可显著降低太湖梅梁湾的湖水营养盐浓度, 吴娟等 ${ }^{[7]}$ 利用静态模拟 实验研究表明, 轮叶黑藻的生长能显著降低水体的氮、磷水平. 国内外开展沉水植物净化水体水质实验多为 静态小试或围隔实验 ${ }^{[8-9]}$, 但自然状态下水体是不断流动. 目前, 对沉水植物修复动态水研究报道较少 ${ }^{[10]}$, 尤其是对水体中沉水植物植物区和无植物区动态流动中的研究更是鲜有报道 ${ }^{[11]}$.

本文以尾水的氮、磷营养盐为净化对象, 设计沉水植物有植物单元和无植物单元串联净化系统, 了解沉 水植物系统不同单元的净化效果, 并探讨系统中有无植物单元串联设计对水体氮、磷营养盐去除的影响, 以 期为沉水植物系统净化农村水体提供参考.

\section{1 材料与方法}

\section{1 实验材料}

实验所用的沉水植物轮叶黑藻 (Hydrilla verticillata) 和苦草(Vallisneria natans)均采集于广州野外采集. 植物经实验条件下驯养适应 $15 \mathrm{~d}$ 后, 选择叶芽根茎齐全、性状统一且含 $15 \sim 18 \mathrm{~cm}$ 健壮顶枝的轮叶黑藻和高 度为 $15 \sim 20 \mathrm{~cm}$ 的苦草幼苗进行实验, 2 种植物均采用扞插法栽种,栽种配置见表 1.

\section{2 实验设计}

1.2.1 水槽设计 实验于 2013 年 3 月 10 日至 7 月 10 日在广州暨南大学温室内的水槽中进行. 实验水槽共计 2 组, 每组水槽面积约为 $3.4 \mathrm{~m}^{2}$, 由 6 个尺寸为 $75 \mathrm{~cm} \times 75 \mathrm{~cm} \times 65 \mathrm{~cm}$ 的单元构成, 分为轮叶黑藻组 $(\mathrm{H} 1 \sim \mathrm{H} 6)$ 和苦草组 $(\mathrm{V} 1 \sim \mathrm{V} 6)$ ( 图 1), 其中轮叶黑藻组无植物单元为 $\mathrm{H} 1 、 \mathrm{H} 3 、 \mathrm{H} 5$, 有植物单元为 $\mathrm{H} 2 、 \mathrm{H} 4 、 \mathrm{H} 6$; 苦草组相 同. 每组水槽通过水体在无植物单元上端进水, 下端出水, 在有植物单元下端进水, 上端出水垂直方向呈对 角的连续流动方式,使 6 个单元形成了无植物区和有植物区循环串联的水槽装置.

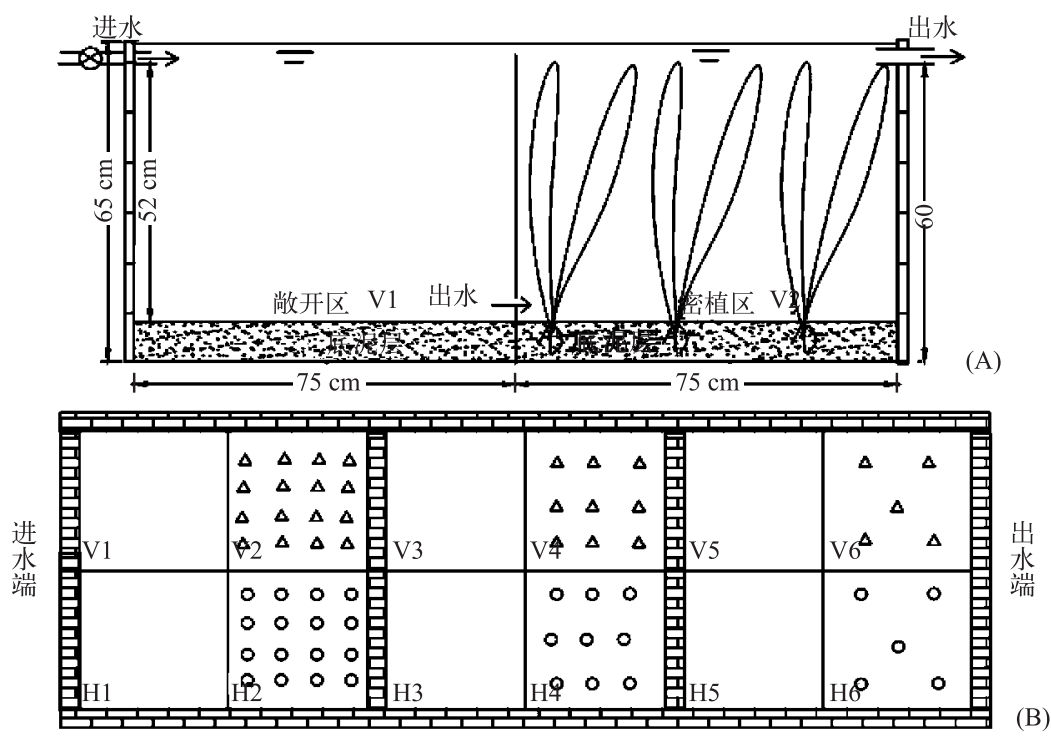

图 1 布水和装置设计流程图

Fig.1 Water distribution design flow chart

1.2 .2 实验底泥及水体设计 实验水槽底部放置厚度为 $8 \sim 12 \mathrm{~cm}$ 的土壤(采自氮、磷营养盐含量相对较低的 广州火炉山山体土壤), 其中土壤背景值总氮 (TN) 含量为 $0.35 \pm 0.04 \mathrm{~g} / \mathrm{kg}$, 总磷 ( TP) 含量为 $0.14 \pm 0.01 \mathrm{~g} / \mathrm{kg}$. 
实验用水参考 Wienßer 等 ${ }^{[12]}$ 污水配置方法, 选择适宜稀释梯度液用于模拟农村池塘污水水体 TN 浓度为 $4.5 \pm 1.4 \mathrm{mg} / \mathrm{L}, \mathrm{TP}$ 浓度为 $0.4 \pm 0.1 \mathrm{mg} / \mathrm{L}$ (进水氮、磷离子浓度见表 2 ). 实验每天进水 $100 \mathrm{~L}$, 进水流量为 10 $\mathrm{L} / \mathrm{h}$, 每天 $10 \mathrm{~h}$.

1.2 .3 水温和光照条件 实验期间水体温度范围为 $20.9 \sim 28.3^{\circ} \mathrm{C}$, 各单元水温差异小于 $2^{\circ} \mathrm{C}$; 温室阴天和晴天 光照范围为 3470 98690 lx.

\section{3 取样与分析方法}

1.3.1 水质分析 实验开始时测定水质初始值, 之后每隔 $5 \mathrm{~d}$ 采集进水和 12 个单元出水口附近水样, 现场测定 水温、 $\mathrm{pH}$ 值、溶解氧 $(\mathrm{DO})$ 浓度 (YSI-Plus, US), 实验室测定总氮 $(\mathrm{TN})$ 、硝态氮 $\left(\mathrm{NO}_{3}^{-}-\mathrm{N}\right)$ 、铵态氮 $\left(\mathrm{NH}_{4}^{+}-\mathrm{N}\right)$ 、叶绿 素 $\mathrm{a}(\mathrm{Chl} . \mathrm{a})$ 和磷酸盐 $\left(\mathrm{PO}_{4}^{3-}-\mathrm{P}\right)$ 浓度等指标, 共采集水样 24 次. 采样及水质分析方法参照文献 [13].

1.3.2 植物测定 沉水植物生长情况于实验初期和实验末期时分别测定, 每次现场测定 6 个有植物单元内植 物鲜重、株高及分藥数. 且在每个植物单元里选择 3 兒代表性植株用纯水冲洗干净称量鲜重, $60^{\circ} \mathrm{C}$ 烘干至恒 重, 计算含水率, 并将植物磨碎过 100 目篎, 测定植物体内的全氮和全磷含量 ${ }^{[14]}$.

1.3.3 微生物测定 实验采用最大可能计数 (Most Probable Number, MPN) 法测定水体、底泥及植物表面硝化细 菌与反硝化细菌总数. 水样采集利用无菌 $100 \mathrm{ml}$ 白色广口塑料瓶在每个单元中水体中层 (约水下 $0.3 \mathrm{~m}$ ) 处取 得 12 个样品; 底泥采集完装人盛有 $100 \mathrm{ml}$ 无菌水的三角瓶中, 置于摇床上振荡 $30 \mathrm{~min}$, 制成均匀悬浊液 12 个 样品; 植物单元内取植物样鲜重 (各个部位) $20 \mathrm{~g}$, 用 $100 \mathrm{ml}$ 无菌水洗脱植物根、茎、叶表面微生物 6 个样品.

\section{4 数据及统计分析}

\subsection{1 相对生长速率 选用相对生长速率 $(R G R)$ 比较不同植物的生长速率, 公式为:}

$$
R G R=\left(\ln W_{2}-\ln W_{1}\right) / t
$$

式中, $W_{2}$ 为第 2 次测定的植物干重 $(\mathrm{g}) ; W_{1}$ 为第 1 次测定的植物干重 $(\mathrm{g}) ; t$ 为 2 次测定的时间间隔 $(\mathrm{d})$.

1.4.2 细菌总数 查 MPN 表, 计算水样、底泥附着和植物附着微生物的细菌总数 ${ }^{[15]}$. 底泥与植物附着微生物 单位为 $\mathrm{kg}^{-1}$; 比较水样细菌总数时, 视 $1 \mathrm{~L}$ 为 $1 \mathrm{~kg}$, 单位为 $\mathrm{L}^{-1}$.

1.4.3 数据处理 数据处理使用 Excel 2007 软件, 统计分析使用 SPSS 17.0 软件, 其中 $P<0.05$ 为差异显著, $P<0.01$ 为差异极显著, 实验数据采用平均值 \pm 标准差表示.

\section{2 实验与分析}

\section{1 轮叶黑藻和苦草生长特性}

轮叶黑藻和苦草栽种初期, 生长状况良好. 轮叶黑藻为枝条分藥, 分藥数由初始 1 条变为 $6.5 \sim 12.3$ 条, 无分株现象, 逐步形成一个顶冠蓬散、底部稀少 (株数不变) 的植物群落; 苦草分雀数由 $5.6 \sim 7.3$ 条增至 8.3 10.3 条, 分株由 20 28 棵增至 52 69 棵, 平均增加株数 $133.1 \%$, 形成底部覆盖较多的 “草坪型” 生长模块 (表 1). 从生长特性上看, 轮叶黑藻对光照竞争压力更大, 过量的顶端枝叶使植物中、下层难以透过光照, 造 成植物光合作用受阻, 影响其生长.

表 1 各净水单元沉水植物的生长特性

Tab.1 The growth of submerged macrophytes in units

\begin{tabular}{|c|c|c|c|c|c|c|c|c|c|c|}
\hline \multirow{2}{*}{$\begin{array}{l}\text { 沉水 } \\
\text { 植物 }\end{array}$} & \multirow[b]{2}{*}{ 区域 } & \multicolumn{4}{|c|}{3 月 10 日 } & \multicolumn{4}{|c|}{7 月 10 日 } & \multirow{2}{*}{$\begin{array}{l}\text { 相对生长 } \\
\text { 速率/ } \mathrm{d}^{-1}\end{array}$} \\
\hline & & $\begin{array}{c}\text { 盖度/ } \\
\%\end{array}$ & $\begin{array}{l}\text { 鲜重/ } \\
\left(\mathrm{g} / \mathrm{m}^{2}\right)\end{array}$ & 株数 & 分藥数 & $\begin{array}{c}\text { 盖度/ } \\
\%\end{array}$ & $\begin{array}{l}\text { 鲜重/ } \\
\left(\mathrm{g} / \mathrm{m}^{2}\right)\end{array}$ & 株数 & 分藥数 & \\
\hline 轮叶 & $\mathrm{H} 2$ & 50 & 72 & 16 & 1 & 100 & 1291 & 16 & 6.5 & 0.024 \\
\hline \multirow[t]{2}{*}{ 黑藻组 } & $\mathrm{H} 4$ & 25 & 40 & 12 & 1 & 100 & 955 & 12 & 8.9 & 0.026 \\
\hline & H6 & 15 & 20 & 6 & 1.7 & 90 & 785 & 6 & 12.3 & 0.030 \\
\hline \multirow[t]{3}{*}{ 苦草组 } & V2 & 50 & 72 & 28 & 5.6 & 75 & 301 & 69 & 8.3 & 0.013 \\
\hline & V4 & 25 & 40 & 28 & 6.0 & 85 & 387 & 54 & 10.3 & 0.019 \\
\hline & V6 & 15 & 20 & 20 & 7.3 & 65 & 171 & 52 & 7.6 & 0.017 \\
\hline
\end{tabular}


实验结束时, 各个单元沉水植物生物量均显著大于实验初期 $(P<0.01)$, 轮叶黑藻组 $\mathrm{H} 2 、 \mathrm{H} 4$ 和 $\mathrm{H} 6$ 单元 生物量增长倍数分别为 $16.9 、 22.9$ 和 38.3 倍, 苦草组 V2、V4 和 V6 单元生物量增长倍数分别为 $3.2 、 8.7$ 和 7.6 倍. 通过对比各单元内沉水植物的相对生长速率 $(R G R)$, 轮叶黑藻组 $\mathrm{H} 6$ 单元生长最快 $\left(0.030 \mathrm{~d}^{-1}\right)$, 显著 高于 $\mathrm{H} 2$ 和 $\mathrm{H} 4$ 单元 $(P<0.05)$; 苦草组 V4 单元生长最快 $\left(0.019 \mathrm{~d}^{-1}\right)$, 显著高于其他单元 $(P<0.05)$, 原因可能 是 $\mathrm{H} 2 、 \mathrm{H} 4$ 和 $\mathrm{V} 2$ 单元植物生长的限制因子为植物过密, 导致植物生长空间和光照受限, 而过密的植物生物 量会影响植物生长. 结果显示, 本实验中轮叶黑樥选择 $20 \mathrm{~g} / \mathrm{m}^{2}$, 苦草选择 $40 \mathrm{~g} / \mathrm{m}^{2}$ 可作为适种密度, 结合植 物生长特性和相对生长速率等因素, 适时收割才能保证植物持续旺盛生长.

\section{2 进、出水水质特征}

随着实验的运行, 沉水植物系统对水体中的 $\mathrm{TN} 、 \mathrm{NO}_{3}^{-}-\mathrm{N} 、 \mathrm{NH}_{4}^{+}-\mathrm{N}$ 和 $\mathrm{PO}_{4}^{3-}-\mathrm{P}$ 浓度有明显的去除效果 $(P<0.01)$, 轮叶黑藻组单元各水质参数的平均去除率分别为 $52.1 \% 、 38.7 \% 、 87.5 \%$ 和 $66.9 \%$, 苦草组分别为 $48.9 \% 、 45.1 \% 、 81.3 \%$ 和 $62.3 \%$. 其中 2 组沉水植物对水体中各参数净化效果略有不同, 轮叶黑藻组对 TN、 $\mathrm{NH}_{4}^{+}-\mathrm{N} 、 \mathrm{PO}_{4}^{3-}-\mathrm{P}$ 的处理效果高于苦草组,对 $\mathrm{NO}_{3}^{-}-\mathrm{N}$ 的处理效果低于苦草组,但 2 组出水水质参数并无显著性 差异, 且 2 组各水质参数间表现出相似的去除趋势.

表 2 实验水槽进水与出水水质比较*

Tab.2 The inflow and outflow water quality comparison experiment

\begin{tabular}{|c|c|c|c|c|c|c|c|c|c|}
\hline \multirow{2}{*}{$\begin{array}{l}\text { 沉水 } \\
\text { 植物 }\end{array}$} & \multirow{2}{*}{$\begin{array}{l}\text { 水质 } \\
\text { 参数 }\end{array}$} & \multicolumn{3}{|c|}{ 进水 } & \multicolumn{3}{|c|}{ 出水 } & \multirow{2}{*}{$\begin{array}{c}\text { 变动率/ } \\
\%\end{array}$} & \multirow[b]{2}{*}{$P$} \\
\hline & & 最小值 & 最大值 & $\begin{array}{c}\text { 平均值土标准差 } \\
(n=23)\end{array}$ & 最小值 & 最大值 & $\begin{array}{c}\text { 平均值士标准差 } \\
(n=23)\end{array}$ & & \\
\hline \multirow[t]{8}{*}{ 轮叶黑藻组 } & 水温 & 19.0 & 29.3 & $24.8 \pm 2.83$ & 19.3 & 29.4 & $25.3 \pm 3.10$ & 2.0 & 0.708 \\
\hline & $\mathrm{pH}$ 值 & 6.7 & 7.5 & $7.1 \pm 0.28$ & 7.2 & 7.8 & $7.5 \pm 0.28$ & 6.4 & 0.015 \\
\hline & DO & 0.7 & 7.9 & $4.8 \pm 2.0$ & 2.8 & 11.3 & $7.4 \pm 2.5$ & 55.9 & 0.001 \\
\hline & Chl.a & 3.2 & 63.7 & $28.4 \pm 22.3$ & 15.1 & 150.7 & $56.4 \pm 46.0$ & 86.5 & 0.028 \\
\hline & $\mathrm{TN}$ & 2.3 & 6.4 & $4.5 \pm 1.4$ & 0.1 & 4.3 & $2.2 \pm 1.5$ & -52.1 & 0.000 \\
\hline & $\mathrm{NO}_{3}^{-}-\mathrm{N}$ & 1.5 & 4.0 & $3.1 \pm 0.9$ & 0.2 & 3.2 & $1.9 \pm 1.2$ & -38.7 & 0.000 \\
\hline & $\mathrm{NH}_{4}^{+}-\mathrm{N}$ & 0.5 & 2.0 & $1.6 \pm 0.6$ & 0.0 & 0.9 & $0.2 \pm 0.2$ & -87.5 & 0.000 \\
\hline & $\mathrm{PO}_{4}^{3-}-\mathrm{P}$ & 0.2 & 0.6 & $0.4 \pm 0.1$ & 0.0 & 0.6 & $0.1 \pm 0.0$ & -66.9 & 0.000 \\
\hline \multirow[t]{8}{*}{ 苦草组 } & 水温 & 18.8 & 28.7 & $25.1 \pm 2.64$ & 19.0 & 29.4 & $25.0 \pm 2.76$ & 0.4 & 0.729 \\
\hline & $\mathrm{pH}$ 值 & 6.7 & 7.8 & $7.2 \pm 0.3$ & 6.8 & 8.7 & $7.6 \pm 0.64$ & 6.2 & 0.027 \\
\hline & DO & 0.3 & 8.0 & $4.7 \pm 2.1$ & 1.3 & 16.7 & $8.0 \pm 4.1$ & 71.4 & 0.006 \\
\hline & Chl.a & 5.2 & 105.9 & $40.3 \pm 31.1$ & 37.5 & 160.6 & $76.8 \pm 33.1$ & 107.6 & 0.002 \\
\hline & $\mathrm{TN}$ & 2.3 & 6.4 & $4.5 \pm 1.4$ & 0.1 & 4.4 & $2.3 \pm 1.3$ & -48.9 & 0.000 \\
\hline & $\mathrm{NO}_{3}^{-}-\mathrm{N}$ & 1.5 & 4.0 & $3.1 \pm 0.9$ & 0 & 3.4 & $1.7 \pm 1.2$ & -45.1 & 0.000 \\
\hline & $\mathrm{NH}_{4}^{+}-\mathrm{N}$ & 0.5 & 2.0 & $1.6 \pm 0.6$ & 0.0 & 0.9 & $0.3 \pm 0.2$ & -81.3 & 0.000 \\
\hline & $\mathrm{PO}_{4}^{3-}-\mathrm{P}$ & 0.2 & 0.6 & $0.4 \pm 0.1$ & 0.0 & 0.3 & $0.1 \pm 0.0$ & -62.3 & 0.000 \\
\hline
\end{tabular}

* 采样分析时间为 2013 年 3-7 月,其中水温单位为 ${ }^{\circ} \mathrm{C}, \mathrm{pH}$ 值无单位,其他水质参数单位为 $\mathrm{mg} / \mathrm{L} ; P$ 值无单位.

\section{3 水体 N、P 的延程变化}

沉水植物系统对水体中的 TN 去除效果显示 (图 2a), TN 浓度随水流沿程方向呈逐级降低的趋势. 统计 分析发现, 轮叶黑藻组有植物单元 TN 的平均净化效率为 $14.8 \%$, 苦草组为 $12.3 \%$, 而 2 组无植物单元平均净 化效率不到 $3.7 \%$, 有植物单元处理水体 TN 效率极显著高于无植物单元 $(P<0.01)$, 但轮叶黑藻组和苦草组 之间并无显著差异 $(P>0.05)$.

沉水植物系统对水体中的 $\mathrm{NH}_{4}^{+}-\mathrm{N}$ 去除效果显示 (图 2b), 随水流沿程方向 $\mathrm{NH}_{4}^{+}-\mathrm{N}$ 浓度先迅速降低, 后 稳定在 $0 \sim 0.5 \mathrm{mg} / \mathrm{L}$ 较低的波动范围内. 轮叶黑藻组有植物单元 $\mathrm{NH}_{4}^{+}-\mathrm{N}$ 平均去除率为 $27.4 \%$, 无植物单元平 均去除率为 $31.4 \%$; 苦草组有植物单元 $\mathrm{NH}_{4}^{+}-\mathrm{N}$ 平均去除率为 $26.3 \%$, 无植物单元为 $38.7 \%$. 统计分析可知, 2 组实验中 $\mathrm{NH}_{4}^{+}-\mathrm{N}$ 去除效率在无植物单元显著高于有植物单元 $(P<0.05)$. 
实验期间, 沉水植物系统 $\mathrm{NO}_{3}^{-}-\mathrm{N}$ 浓度随着水流沿程方向呈现先升高后逐渐降低的趋势 (图 2c ). 这可能 是因为在前几个单元内水体中硝化作用的增量高于被沉水植物直接吸收利用及反硝化过程去除量而引起 的 $\mathrm{NO}_{3}^{-}-\mathrm{N}$ 积累, 当单元内 $\mathrm{NH}_{4}^{+}-\mathrm{N}$ 浓度降低之后, $\mathrm{NO}_{3}^{-}-\mathrm{N}$ 浓度开始呈现降低的趋势. 轮叶黑藻组有植物单元 $\mathrm{NO}_{3}^{-}-\mathrm{N}$ 浓度平均去除率为 $12.1 \%$, 无植物单元平均去除率为 $2.4 \%$; 苦草组有植物单元 $\mathrm{NO}_{3}^{-}-\mathrm{N}$ 平均去除率为 $14.8 \%$, 无植物单元为 $1.3 \%$. 统计分析可知, $\mathrm{NO}_{3}^{-}-\mathrm{N}$ 去除效率在有植物单元内极显著高于无植物单元 $(P<0.01)$.

沉水植物系统对水体中的 $\mathrm{PO}_{4}^{3-}-\mathrm{P}$ 去除效果显示 (图 2d), 随水流沿程方向 $\mathrm{NH}_{4}^{+}-\mathrm{N}$ 浓度呈现逐级降低的 趋势. 统计分析发现, 当污水流经实验有植物单元内 $\mathrm{PO}_{4}^{3-}-\mathrm{P}$ 轮叶黑藻组平均去除率为 $13.3 \%$, 苦草组平均去 除率为 $15.7 \%$, 而在无植物单元 $\mathrm{PO}_{4}^{3-}-\mathrm{P}$ 平均去除率只有 $8 \%$ 左右, 极显著小于有植物单元 $(P<0.01)$.
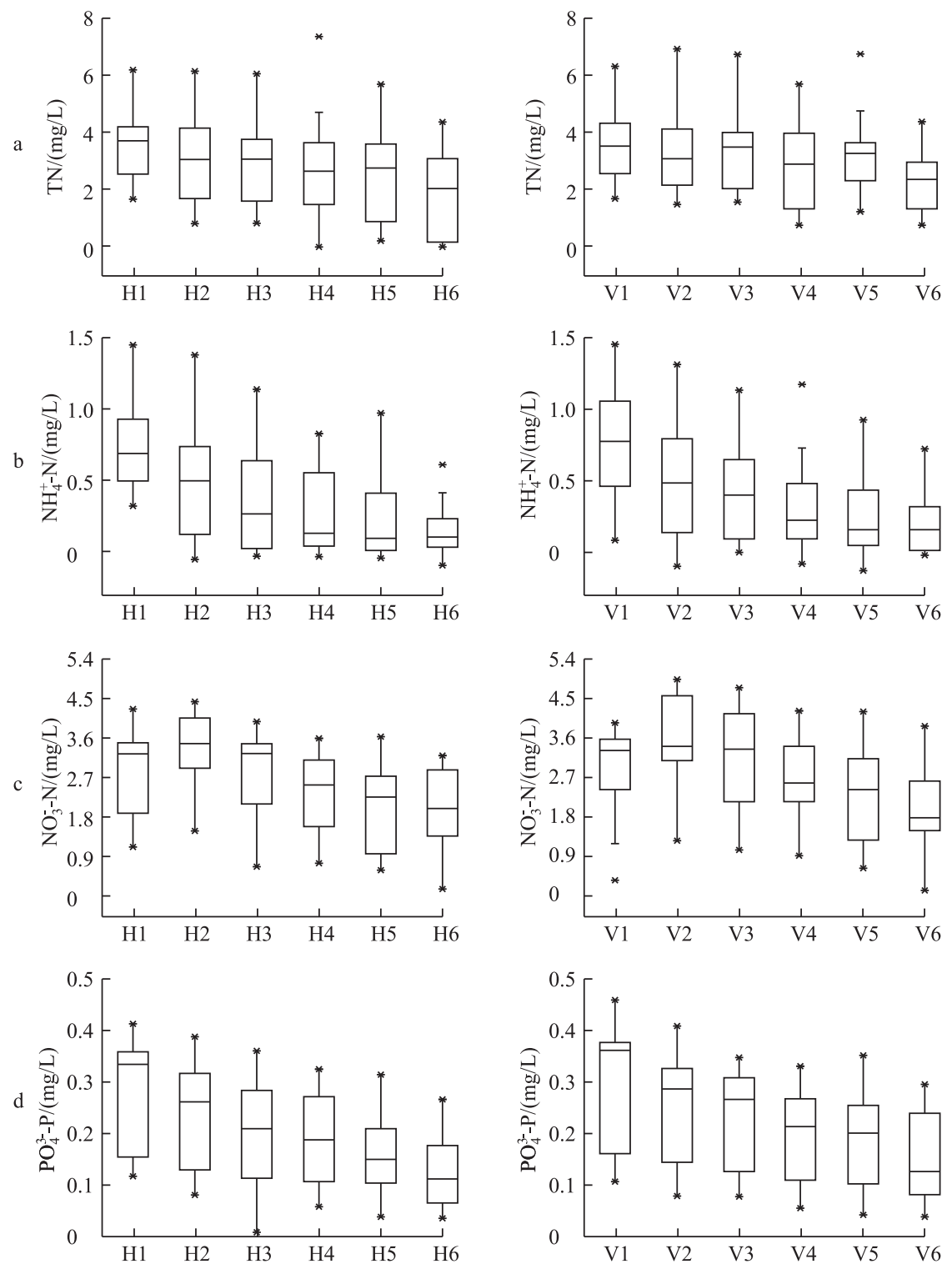

图 2 轮叶黑藻组和苦草组各净水单元氮、磷浓度变化

Fig.2 Changes of water quality in water purification unit of Hydrilla verticillata and Vallisneria natans 


\section{4 水体 DO 和 $\mathrm{pH}$ 值的空间变化}

实验初期 2 组沉水植物单元水体 DO 浓度均较低, 随着实验的进行, DO 浓度逐渐升高. 整个实验期间, 轮叶黑藻组水体 DO 浓度变化范围分别为 $1.4 \sim 8.9 \mathrm{mg} / \mathrm{L}$, 苦草组为 $0.6 \sim 12.6 \mathrm{mg} / \mathrm{L}$. 其中轮叶黑藻组有植物 单元和无植物单元 DO 浓度平均值分别为 5.5 和 $6.8 \mathrm{mg} / \mathrm{L}$, 苦草组分别为 5.1 和 $7.4 \mathrm{mg} / \mathrm{L}$. 统计发现, 沉水植 物有植物单元 DO 浓度显著小于无植物单元 $(P<0.05)$. 实验前期各单元水槽中水体 $\mathrm{pH}$ 值无明显变化, 均在 $6.5 \sim 7.5$ 之间,到实验中后期, $\mathrm{pH}$ 值逐渐升高( 图 3).
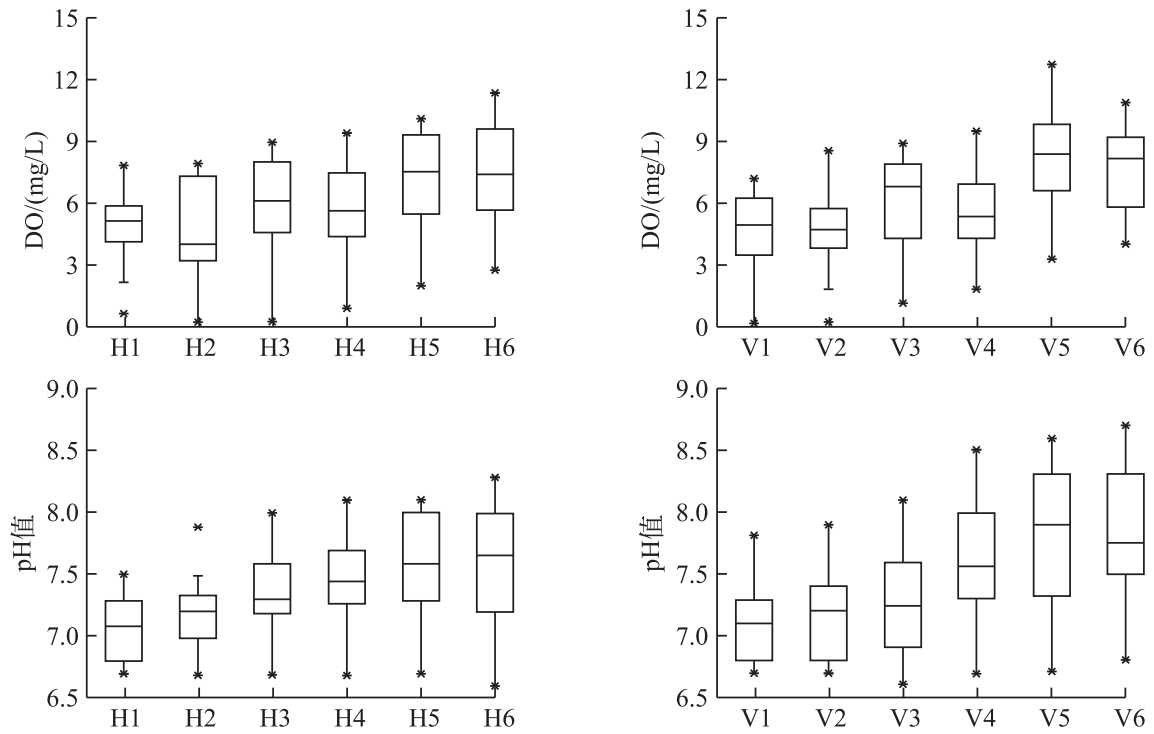

图 3 轮叶黑藻组和苦草组各净水单元 $\mathrm{pH}$ 值和 DO 浓度变化

Fig.3 Changes of $\mathrm{pH}$ and DO concentrations in water purification unit of Hydrilla verticillata and Vallisneria natans

\section{5 硝化、反硝化细菌在系统中的分布特征}

对比 2 组实验组的水体和底泥微生物含量分析, 底泥表面硝化细菌和反硝化细菌总数均显著高于水体 $(P<0.01)$ (表 3), 表明底泥表面为微生物生长提供了必要的营养与能量, 是系统硝化与反硝化作用的主要 位点. 轮叶黑藻组和苦草组底泥表面的硝化细菌和反硝化细菌总数无显著差异 $(P>0.05)$.

表 3 轮叶黑藻组和苦草组有无植物单元硝化与反硝化细菌总数 $\lg [n(M P N)]$ 的差异性分析"

Tab.3 The nitrification and denitrification bacteria $\lg [\mathrm{n}(\mathrm{MPN})]$ in plant and open cells of Hydrilla verticillata and Vallisneria natans

\begin{tabular}{|c|c|c|c|c|c|c|}
\hline \multirow{2}{*}{ 类型 } & \multirow{2}{*}{ 区域 } & \multicolumn{2}{|c|}{ 轮叶黑藻组 } & \multicolumn{2}{|c|}{ 苦草组 } & \multirow{2}{*}{$P$ 值 $(n=6)$} \\
\hline & & 有植物单元 & 无植物单元 & 有植物单元 & 无植物单元 & \\
\hline \multirow[t]{2}{*}{ 硝化细菌 } & 水体 & 1.99 & 2.19 & 1.99 & 2.13 & 0.72 \\
\hline & 底泥 & 4.04 & 4.24 & 3.65 & 4.01 & 0.03 \\
\hline \multirow[t]{2}{*}{ 反硝化细菌 } & 水体 & 2.59 & 2.12 & 1.97 & 2.04 & 0.78 \\
\hline & 底泥 & 5.06 & 4.43 & 5.53 & 5.30 & 0.02 \\
\hline
\end{tabular}

$* P<0.01$ 表示极显著差异; $P<0.05$ 表示显著差异.

对比 2 组实验组有无植物单元微生物含量分析, 植物单元与无植物单元水体硝化细菌与反硝化细菌总 数无显著差异 $(P>0.05)$, 硝化细菌总数在无植物单元略大于植物单元. 而底泥中植物单元硝化细菌总数显 著小于无植物区域 $(P<0.03)$, 反硝化细菌总数植物单元显著小于无植物单元 $(P<0.02)$. 结果表明, 在无植物 单元水体和底泥发生硝化作用较为显著, 而在有植物单元内底泥发生反硝化作用较为显著, 水体中的反硝 
化强度也有所增强.

生物降解是系统中 $\mathrm{N}$ 去除的重要途径, 硝化细菌是以 $\mathrm{NH}_{4}^{+}-\mathrm{N}$ 为降解底物的微生物, $\mathrm{NH}_{4}^{+}-\mathrm{N}$ 在硝化细菌 的作用下转变为 $\mathrm{NO}_{3}^{-}-\mathrm{N}$, 而 $\mathrm{NO}_{3}^{-}-\mathrm{N}$ 在反硝化细菌的作用下转变为 $\mathrm{NO}_{2}^{-}-\mathrm{N}$, 最后变为 $\mathrm{N}_{2}$ 或 $\mathrm{NO}_{2}$ 从水体中去 除 ${ }^{[16]}$. 硝化细菌总数与 $\mathrm{TN}$ 浓度 $(P<0.016)$ 和 $\mathrm{NH}_{4}^{+}-\mathrm{N}$ 浓度 $(P<0.021)$ 均存在显著正相关, 与 $\mathrm{NO}_{3}^{-}-\mathrm{N}$ 浓度无显 著相关性 $(P<0.067)$; 而反硝化细菌与 $\mathrm{TN}$ 浓度 $(P<0.001)$ 和 $\mathrm{NO}_{3}^{-}-\mathrm{N}$ 浓度 $(P<0.001)$ 均存在极显著正相关, 与 $\mathrm{NH}_{4}^{+}-\mathrm{N}$ 浓度存在极显著负相关 $(P<0.002)$. 结果表明, $\mathrm{N}$ 的去除与微生物反硝化作用存在显著相关性, 无 植物区硝化作用与有植物区的反硝化作用, 对系统中 $\mathrm{N}$ 的彻底去除提供良好条件, 也在一定程度上验证有 植物单元和无植物单元串联设计的优越性.

\section{3 讨论}

通过 6 个月的连续监测数据, 分析实验水槽中 $\mathrm{DO}$ 浓度、 $\mathrm{pH}$ 值、叶绿素 $\mathrm{a}$ 浓度、植物生物量、植物面积与 水质氮、磷去除负荷的关系, 对找出水体营养盐去除机制, 评价沉水植物在池塘水体中的生态修复作用及其 与无植物区域串联之间的关系非常重要.

沉水植物生物量与水体中的 $\mathrm{TN} 、 \mathrm{NO}_{3}^{-}-\mathrm{N} 、 \mathrm{NH}_{4}^{+}-\mathrm{N} 、 \mathrm{PO}_{4}^{3-}-\mathrm{P}$ 去除负荷均存在显著正相关 $(P<0.05)$, 表明水 体中营养盐浓度的降低与沉水植物的吸收存在直接关系 (表 4), 植物在生长过程中, 可通过根系和茎叶直接 吸收水体中的氮、磷营养盐合成植物蛋白所需的有机氮和有机磷 ${ }^{[17]}$. 本实验条件下, 轮叶黑藻组生物量显 著高于苦草组, 表明轮叶黑藻体内能富集更多的 $\mathrm{TN} 、 \mathrm{PO}_{4}^{3-}-\mathrm{P}$, 也许是导致轮叶黑藻组出水效率高于苦草的一 个重要原因 ${ }^{[18]}$. 另一方面, 植物在生长过程中可以通过光合作用和呼吸作用影响水体环境, 从而调节了原 有的环境因子 ( DO 、 pH 值等), 且水体中氮、磷去除受到水环境条件的影响 ${ }^{[19]}$. 水体中氮的去除机制主要有 3 个方面, 即硝化与反硝化、沉降吸附和生物吸收作用, 其中硝化和反硝化作用最重要 ${ }^{[20]}$. 硝化细菌将 $\mathrm{NH}_{4}^{+}-\mathrm{N}$ 在 有氧环境下转化为 $\mathrm{NO}_{3}^{-}-\mathrm{N}$, 反硝化细菌在缺氧环境下, 利用有机碳源为电子供体, $\mathrm{NO}_{3}^{-}-\mathrm{N}$ 为电子接受者而还 原成 $\mathrm{NO} 、 \mathrm{NO}_{2}$ 及 $\mathrm{N}_{2}$ 排出. $\mathrm{DO}$ 浓度与 $\mathrm{TN} 、 \mathrm{NO}_{3}^{-}-\mathrm{N} 、 \mathrm{PO}_{4}^{3-}-\mathrm{P}$ 去除负荷呈现负相关、与 $\mathrm{NH}_{4}^{+}-\mathrm{N}$ 去除负荷呈正相关 (表 4), 表明当污水从上端位孔流经无植物区域时较高的 $\mathrm{DO}$ 和 $\mathrm{NH}_{4}^{+}$浓度增加了水体的硝化强度, 这可能是

表 4 沉水植物各环境影响因子之间的相关性

Tab.4 Correlations between environmental impact factors of submerged plants

\begin{tabular}{|c|c|c|c|c|c|c|c|c|c|}
\hline $\begin{array}{l}\text { 沉水 } \\
\text { 植物 }\end{array}$ & 参数 & $\mathrm{pH}$ 值 & DO & $\begin{array}{c}\text { 沉水植物 } \\
\text { 面积 }\end{array}$ & Chl.a & 生物量 & $\mathrm{TN}$ & $\mathrm{NO}_{3}^{-}-\mathrm{N}$ & $\mathrm{NH}_{4}^{+}-\mathrm{N}$ \\
\hline \multirow[t]{8}{*}{ 黑藻组 } & DO & $0.96^{* *}$ & & & & & & & \\
\hline & 沉水植物面积 & -0.27 & $-0.38^{*}$ & & & & & & \\
\hline & Chl.a & 0.37 & 0.51 & -0.59 & & & & & \\
\hline & 生物量 & -0.38 & -0.41 & $0.80^{*}$ & -0.19 & & & & \\
\hline & $\mathrm{TN}$ & -0.29 & -0.44 & $0.79^{*}$ & -0.41 & $0.68^{*}$ & & & \\
\hline & $\mathrm{NO}_{3}^{-}-\mathrm{N}$ & -0.18 & -0.27 & $0.85^{* *}$ & -0.33 & $0.89^{* * *}$ & $0.89^{* *}$ & & \\
\hline & $\mathrm{NH}_{4}^{+}-\mathrm{N}$ & 0.41 & 0.50 & -0.27 & -0.18 & $0.77^{*}$ & 0.66 & $0.79^{*}$ & \\
\hline & $\mathrm{PO}_{4}^{3-}-\mathrm{P}$ & 0.06 & 0.01 & $0.83^{* *}$ & -0.28 & $0.91^{* *}$ & 0.62 & $0.90^{* *}$ & $0.67^{*}$ \\
\hline \multirow[t]{8}{*}{ 苦草组 } & DO & $0.98^{* * *}$ & & & & & & & \\
\hline & 沉水植物面积 & -0.01 & $-0.49^{*}$ & & & & & & \\
\hline & Chl.a & 0.29 & 0.14 & 0.10 & & & & & \\
\hline & 生物量 & -0.21 & -0.22 & $0.75^{*}$ & -0.19 & & & & \\
\hline & $\mathrm{TN}$ & -0.49 & -0.64 & $0.77^{*}$ & -0.19 & $0.84^{* *}$ & & & \\
\hline & $\mathrm{NO}_{3}^{-}-\mathrm{N}$ & -0.15 & -0.07 & $0.64^{*}$ & 0.05 & $0.65^{*}$ & $0.72 *$ & & \\
\hline & $\mathrm{NH}_{4}^{+}-\mathrm{N}$ & 0.41 & 0.35 & -0.12 & -0.06 & 0.28 & 0.38 & -0.10 & \\
\hline & $\mathrm{PO}_{4}^{3-}-\mathrm{P}$ & -0.26 & -0.37 & $0.86^{* *}$ & -0.06 & $0.81^{* *}$ & $0.78^{*}$ & $0.73 *$ & 0.27 \\
\hline
\end{tabular}

**表示在 0.01 水平 (双侧) 上显著相关; * 表示在 0.05 水平 (双侧) 上显著相关. 
实验水槽 $\mathrm{NH}_{4}^{+}$迅速减少的主要原因 ${ }^{[21]}$, 而下端孔流经有植物区域内, 充足的 $\mathrm{NO}_{3}^{-}$和相对缺氧的环境提供反 硝化的条件,从而增大水体中 $\mathrm{TN} 、 \mathrm{NO}_{3}^{-}-\mathrm{N}$ 的去除.

轮叶黑藻组和苦草组植物分别设置高、中、低 3 个栽种覆盖度, 结果显示, 除 H2、H4 区域沉水植物在生 长过程中因空间受限存在轻微的发黄以外, 其他均迅速生长且很快高于原来设置的最大密度, 从 DO 、 $\mathrm{pH}$ 值 和微生物含量看出, 植物存在营造出有别于无植物单元的降解 $\mathrm{N} 、 \mathrm{P}$ 过程环境. 沉水植物栽种面积是一个可 以调控改变水体中 $\mathrm{N} 、 \mathrm{P}$ 浓度去除的影响因素 ${ }^{[22]}$. 分析沉水植物面积与水质参数的相关性可知, 其与 $\mathrm{TN}$ 、 $\mathrm{NO}_{3}^{-}-\mathrm{N} 、 \mathrm{PO}_{4}^{3-}-\mathrm{P}$ 浓度呈显著正相关, 与 $\mathrm{NH}_{4}^{+}-\mathrm{N}$ 浓度呈负相关. 表明沉水植物生物量在一定范围内, 沉水植物 面积的持续增加虽然可以显著降低水体中的 $\mathrm{NO}_{3}^{-}-\mathrm{N} 、 \mathrm{PO}_{4}^{3-}-\mathrm{P}$ 浓度, 但对 $\mathrm{NH}_{4}^{+}-\mathrm{N}$ 的去除不明显, 这对于处理 高 $\mathrm{NH}_{4}^{+}-\mathrm{N}$ 浓度的农村生活废水不太适宜, 且水体大面积的水生植物收割不合理很容易使得植物残体淤积于 池底, 造成更多的污染物质甚至造成生物累积而引发毒害等问题 ${ }^{[23]}$. 本实验地处华南热带亚热带地区广 州, 温度较高, 植物生长迅速, 实验中植物盖度为 $25 \%$ 的水槽生长情况和处理能力均比较理想, 与 Reed $^{[25]}$ 建 议水生植物占水体全部面积的 $25 \%$ 35\% 基本一致.

\section{4 结论}

1) 2 种沉水植物在本实验污水浓度和植物密度下, 均可旺盛生长, 通过收割轮叶黑藻可带走水体中的氮 为 $1.6 \sim 3.3 \mathrm{~g} / \mathrm{m}^{2}$, 磷为 $0.27 \sim 0.57 \mathrm{~g} / \mathrm{m}^{2}$; 苦草带走的氮为 $0.3 \sim 0.5 \mathrm{~g} / \mathrm{m}^{2}$, 磷为 $0.08 \sim 0.12 \mathrm{~g} / \mathrm{m}^{2}$. 轮叶黑藻和苦 草适种植密度分别为 20 和 $40 \mathrm{~g} / \mathrm{m}^{2}$.

2) 轮叶黑藻组 $\mathrm{TN} 、 \mathrm{NO}_{3}^{-}-\mathrm{N} 、 \mathrm{NH}_{4}^{+}-\mathrm{N}$ 和 $\mathrm{PO}_{4}^{3-}-\mathrm{P}$ 平均去除率分别达到 $52.1 \% 、 38.7 \% 、 87.5 \%$ 和 $66.9 \%$, 苦草 组平均去除率分别为 $48.9 \%$ 、 $45.1 \% 、 81.3 \%$ 和 $62.3 \%$.

3) 有植物单元对 $\mathrm{NO}_{3}^{-}-\mathrm{N}$ 的去除率高于无植物单元, 对 $\mathrm{NH}_{4}^{+}-\mathrm{N}$ 去除率低于无植物区, 表明适当的无植物 水域可促进 $\mathrm{NH}_{4}^{+}-\mathrm{N}$ 的硝化作用,且有无植物单元串联更有利于水体中氮的去除.

\section{5 参考文献}

[ 1 ] Sun Qingye, Ma Xiuling, Yang Guide et al. Studies on nitrogen, phosphorus and organic matter in ponds around Chaohu Lake. Environmental Science, 2010, 31(7) : 110-1515(in Chinese with English abstract). DOI: 10.13227/j.hjkx.2010. 07.015. [孙庆业，马秀玲，阳贵德等.巢湖周围池塘氮、磷和有机质研究.环境科学, 2010, 31(7): 1510-1515.]

[ 2 ] Hough RA, Fornwall MD, Negele BJ et al. Plant community dynamics in a chain of lakes-principal factors in the decline of rooted macrophytes with eutrophication. Hydrobiologia, 1989, 173(3) : 199-217.

[ 3 ] Gao Yunni, Liu Biyun, Wang Jing et al. Allelopathic effects of phenolic compounds released by Vallisneria spiralis on Microcystis aeruginosa. J Lake Sci, 2011, 23(5) : 761-766( in Chinese with English abstract). DOI: 10.18307/2011.0514. [高云霓, 刘碧云, 王静等. 苦草(Vallisneria spiralis) 释放的酚酸类物质对铜绿微囊藻 (Microcystis aeruginosa) 的化 感作用.湖泊科学, 2011, 23(5): 761-766.]

[ 4 ] Melzer A. Aquatic macrophytes as tools for lake management. Hydrobiologia, 1999, 395/396: 181-190.

[ 5 ] Wang Liqing, Li Yan, Zhang Ruilei. The purification of Lake Dianshan water quality with six species of submerged macrophyte systems. Journal of Agro-Environment Science, 2008, 27(3): 1134-1139(in Chinese with English abstract). [王丽 卿, 李燕, 张瑞雷. 6 种沉水植物系统对淀山湖水质净化效果的研究. 农业环境科学学报, 2008, 27 (3): 1134-1139. ]

[ 6 ] Lei Zexiang, Xie YF, Liu ZW et al. Study on the purification of eutrophicated water with aquatic macrophytes. Journal of Anhui Agricultural Sciences, 2006, 34(3) : 553-554(in Chinese with English abstract). [雷泽湘, 谢贻发, 刘正文等. 大型水生植物对富营养化湖水净化效果的试验研究.安徽农业科学, 2006, 34(3): 553-554.]

[ 7 ] Wu Juan, Wu Zhenbin, Cheng Shuiping. Effect of Hydrilla verticillata on characteristics of water and sediment and removals of nutrition. Acta Hydrobiologica Sinica, 2009, 33(4) : 589-595 (in Chinese with English abstract). DOI: 10.3724/ SP.J0000.2009.40589. [ 吴娟, 吴振斌, 成水平. 轮叶黑藻对水体和沉积物理化性质的改善和营养元素的去除作用. 水生生物学报, 2009, 33(4): 589-595.]

[ 8 ] Jukka H, Leena N. Effects of submerged macrophytes on sediment resuspension and internal phosphorus loading in Lake Hiidenvesi( southern Finland).Water Research, 2003, 37: 4468-4474. 
[ 9 ] Wu Zhenbin, Qiu Dongru, He Feng et al. Effects of rehabilitation of submerged macrophytes on nutrient level of a eutrophic lake. Chinese Jouranl of Applied Ecology, 2003, 14(8): 1351-1353 (in Chinese with English abstract). DOI: 10. 13287/j.1001-9332.2003.0301. [ 吴振斌, 邱东茹, 贺锋等. 沉水植物重建对富营养水体氮磷营养水平的影响. 应用 生态学报, 2003, 14(8): 1351-1353.]

[10] Wang Weihong, Ji Min. The restoration of submerged macrophytes for improving water quality in a reclaimed wastewater river in Tianjin Binhai new area, China. Journal of Agro-Environment Science, 2007, 26 (6) : 2292-2298( in Chinese with English abstract). [王卫红, 季民. 滨海再生水河道中沉水植物的恢复对水质的改善.农业环境科学学报, 2007,26 (6) : 2292-2298.]

[11] Qin Boqiang. Principles and approach for lake ecological restoration. Acta Ecologica Sinica, 2007, 27(11) : 4848-4858 (in Chinese with English abstract). [ 秦伯强. 湖泊生态恢复的基本原理与实现. 生态学报, 2007, 27 (11): 4848-4858.]

[12] Wienßer A, Kappelmeyer U, Kuschk P et al. Influence of the redox condition dynamics on the removal efficiency of a laboratory-scale constructed wetland. Water Research, 2005, 39: 248-256.

[13] State Environmental Protection Administration ed. Water and wastewater monitoring and analysis methods: 4th edition. Beijing: China Environmental Science Press, 2002: 88-285 (in Chinese). [ 国家环境保护总局. 水和废水监测分析方法 (第 4 版). 北京: 中国环境科学出版社, 2002: 88-285.]

[14] Wu Jianzhi, Ge Ying, Wang Xiaoyue. UV absorptio photo metric determin ation of total nitrogen in plant after $\mathrm{K}_{2} \mathrm{~S}_{2} \mathrm{O}_{8}$ oxidation. Physical Testing: Chemical Analysis, 2000, 36(4) : 166-167( in Chinese with English abstract). [ 吴建之, 葛溁, 王晓月. 过硫酸钾氧化吸光光度法测定植物总氮.理化检验: 化学分册, 2000, 36(4): 166-167.]

[15] Xu Guanghui, Zheng Hongyuan eds. Agricultural microbiology experimental technology. Beijing: Beijing Agriculture Press, 1986( in Chinese). [ 徐光辉, 郑洪元. 农业微生物学实验技术. 北京: 农业出版社, 1986. ]

[16] Sundberg C, Tonderski K, Lindgren PE. Potential nitrification and denitrification and the corresponding composition of the bacterial communities in a compact constructed wetland treating landfill leachates. Water Science and Technology, 2007, 56: 159-166.

[17] Peterson SB, Teal JM. The role of plants in ecologically engineered wastewater treatment systems. Ecological Engineering, 1996, 6(2): 137-148.

[18] Xie Yifa, Hu Yaohui, Liu Zhengwen et al. Effects of sediment resuspension on the growth of submerged plants. Acta Scientiae Circumstantiae, 27(1): 18-22(in Chinese with English abstract). [ 谢贻发, 胡耀辉, 刘正文等. 沉积物再悬浮对 沉水植物生长的影响研究. 环境科学学报, 2007, 27(1): 18-22.]

[19] Hu Lian, Wang Chengyan, Shen Zhenfeng. In situ enclosure experiment for purification ability of the submerged plants in Yunlonghu Reservoir. Journal of Hydroecology, 2008, 29(2) : 17-21 (in Chinese with English abstract). DOI: 10.15928/ j.1674-3075.2008.06.003. [胡莲, 万成炎, 沈振锋. 云龙湖水库沉水植物净化水质的原位围隔试验. 水生态学杂志, $2008,29(2): 17-21$.

[20] Saunders DL, Kalff J. Nitrogen retention in wetlands, lakes and rivers. Hydrobiologia, 2001, 443 : 205-212.

[21] Peder GE, Weisner SEB. An experimental study on effects of submersed macrophytes on nitrification and denitrification in ammonium-rich aquatic system. Limnology and Oceanography, 1999, 44(8) : 1993-1999.

[22] Dai YR, Jia CR, Liang W et al. Effects of the submerged macrophyte Ceratophyllum demersum L. on restoration of a eutrophic waterbody and its optimal coverage. Ecological Engineering, 2012, 40: 113-116.

[23] Zhu Qingshun. On the dynamics of the aquatic vegetation in Changdang Hu Lake with reference to fishery effect. Journal of Fisheries of China , 1988, 13(1) : 24-35(in Chinese with English abstract). [ 朱清顺. 长荡湖水生植被动态及其渔业 效应. 水产学报, 1988, 13(1): 24-35.]

[24] Chen Qichun, Li Zhengkui, Wang Yichao et al. Applied study of the submerged macrophytes bed-immobilized bacteria in drinking water restoration. Environmental Science, 2012, 33(1): 83-87 (in Chinese with English abstract) DOI: 10. 13227/j.hjkx.2012.01.027. [ 陈祈春, 李正魁, 王易超等. 沉水植物床-固定化微生物技术在水源地修复中的应用研 究. 环境科学, 2012, 33(1): 83-87.]

[25] Reed SC, Brown D. Subsurface flow wetlands: A performance evaluation. Water Environment Research, 1995, 67: 244-248. 